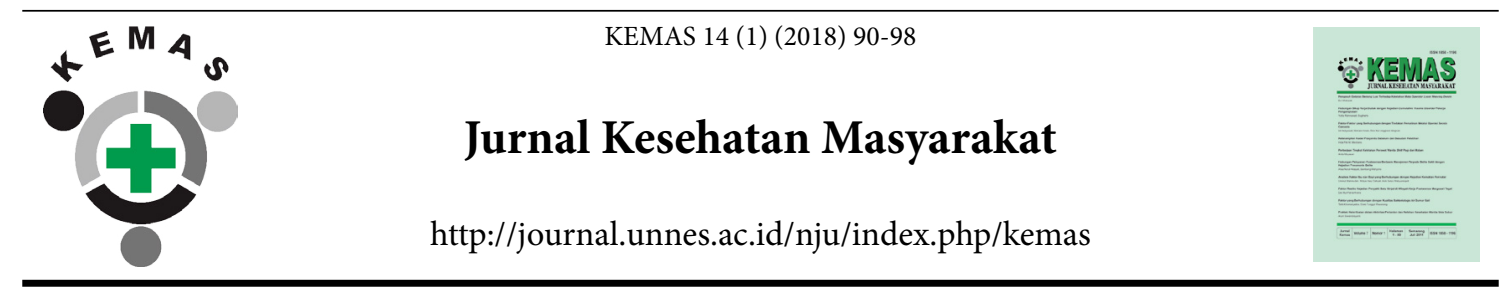

\title{
Position and Chance of Indonesia Family Planing to Achieve RPJMN 2015-2019 and FP2020 Targets
}

\author{
Anggriyani Wahyu Pinandari ${ }^{1 凶}$, Siswanto Agus Wilopo ${ }^{2}$ \\ ${ }^{1}$ Center for Reproductive Health, Faculty of Medicine, Universitas Gadjah Mada M, Indonesia \\ ${ }^{2}$ Biostatistics, Epidemiology and Population Health, Faculty of Medicine, Universitas Gadjah Mada M, \\ Indonesia
}

\section{Article Info \\ Article History: Submitted April 2017 Accepted January 2018 Published July 2018 \\ Keywords: \\ Family planning, con- \\ traceptive method, \\ $\mathrm{CPR}$, unmet need \\ DOI \\ https://doi.org/10.15294/ \\ kemas.v14i1.9466}

\begin{abstract}
Indonesia's commitment at London Summit 2012 was to reduce TFR by increasing contraceptive users by 2020 . This paper aimed to estimate the number, trend and possibility to achieve RPJMN and FP2020 targets in Indonesia. This was a descriptive study using secondary data from Indonesia national survey. Data are presented in line, bar, and pie graphs, also table to explain trend and possibility of Indonesia FP to achieve 2020 targets. Using 2012 data as the baseline, RPJMN and FP2020 targets will be achieved if CPR grows 0.5 point/year. However, recent growth was insufficient, only 0.3 additional points. The current CPR is behind the target and 1 point/year growth rate is needed to approximate the target trajectory. Based on three surveys in 2015 (PMA, SUSENAS and SUPAS), Indonesia's CPR was predicted to be $61.1 \%$ on 2020 . This is five points lower than the 2020 target, 66.3\%. This discrepancy shows that Indonesia would not achieve FP target on RPJMN 2015-2019. Based on recent survey in 2015, CPR trajectory is predicted to be 5 points below the target. 1.5 points annual growth is needed to achieve the 2020 goals.
\end{abstract}

\section{Introduction}

London summit on July 11, 2012 brought new spirit for various stakeholders to refocus on family planning (FP). The aim of this commitment is to increase contraceptive user by 2020 . The importance of universal access for reproductive health has been recognized to be an important part to achieve the Millennium Development Goals since International Conference on Population and Development (ICPD), in Cairo, Egypt, in 1994 (Moore et al., 2015; Nugroho et al., 2017). Increasing the number of contraception users in developing countries has reduced maternal mortality ratio (MMR) by $40 \%$ in the last 20 years through a decrease in the numbers of unwanted pregnancy (Cleland et al., 2015). On 2001, a study on contraception use and prospective unmet need among postpartum women in 27 countries using Demographics Health Survey (DHS) showed that $95 \%$ postpartum women did not want to get pregnant in the next 2 years and $65 \%$ among them were potentially unmet need for contraceptive method. This condition, if improperly handled, will increase the incidence of unwanted pregnancy and worse pregnancy outcome (Ross \& Winfrey, 2001).

Contraception usage will improve perinatal outcome and child survival, especially trough pregnancy spacing mechanism 
(Ayuningtyas et al., 2015). Pregnancy interval less than 20 months increase the risk of premature birth, low birth weight (LBW), fetal death and infant mortality (Cleland et al., 2015). A systematic review by Conde Agudelo stated that mother's health is affected by inadequate pregnancy interval. Short pregnancy interval is correlated with uterine rupture and uteroplacental bleeding disorders (Conde-Agudelo et al., 2007).

Global awareness on the important of family planning program for the health of women and child initiated a global commitment called FP2020, where Indonesia is involved. The government followed this commitment by making TFR reduction and contraceptive prevalent use (CPR) as the main national family planning target. Indonesia's population and family planning strategy is to improve the quality of family planning resources and usage by providing free access of family planning service and commodity throughout the country through National Health Insurance (NHI) scheme. They also committed to invest more on family planning program, including allocation of family planning resources in provinces with high population density and TFR, and located in remote and border areas. The government will expand access and choice of contraceptive methods with service improvement in public and private clinics and encourage the usage of long-term and postpartum contraceptive methods. The overall impact was measured in 8 family planning indicators in National Medium Development Plan (RPJMN) 2015-2019 and 17 indicators of FP2020.

Four years after the commitment, there was no data and analysis that provide information on Indonesia's current position toward the goals. This article aimed to provide an analysis of Indonesia's position and possibility to achieve the 2020 targets.

Methods

This research was a descriptive study using secondary data of three Indonesia national surveys called Indonesia Demography and Health Survey (IDHS), the Inter-Census Survey (SUPAS), National Social Economic Survey (SUSENAS) and Performance Monitoring and Accountability 2020 (PMA2020) survey. These data were analyzed using software developed by Track20 to determine the best estimate for 2015-2019 RPJMN family planning indicators and Family Planning 2020 (FP2020) (detail indicator can be seen in Table 1). Track20 is part of FP2020 activities aimed to provide data and annual projections of progress achievements of FP2020 17 core indicators. There are threeTrack20 software that used in this study, FPET for data preparation, online FPET calculation and Core Indicator 1-9 Calculator.

The first step was to install the FPET data preparation. This tool required CPR and $\mathrm{mCPR}$ numbers from all national data resources that are obtainable. This study include all national survey data from 1973 to 2015. In 2015, Indonesia has three CPR and mCPR estimation numbers based on three different national surveys. The data obtained was converted into CSV format and then uploaded to online FPET calculation. This online instrument produced estimation of some indicators of family planning using Hierarchical Bayesian Method approach. Estimation of demand of modern contraceptive method, mCPR, CPR, and unmet need must be downloaded and inserted to the third instrument, the Core Indicator 1-9 Calculator, which will produce indicator numbers 1-9 of FP2020. While indicators number 10-17 were taken directly from the PMA2020 survey results which was the annual data collection activities of FP2020. We also made adjustment for some data to produce single estimation and consider all possible data resources.

\section{Results and Discussion}

In general, there was no exact number for the target of Indonesia's 17 indicators of FP2020. This differs from the RPJMN indicators which has definite annual targets starting from 2015 until 2019. For 2020, researchers conducted an adjustment taking into account the annual growth target of CPR to obtain estimates RPJMN 2020. In Table 1, except TFR and percent of LARC user, the other five indicators of RPJMN were below the set target.

The $31 \mathrm{CPR}$ and mCPR data from national surveys since 1973-2015 were used to estimate family planning indicator of RPJMN and FP2020. FP2020 introduced additional user as a new indicator to provide better perspective about family planning program evaluation. In the old approach, family planning stakeholders 
Table 1.Family Planning Main Indicator of FP2020 and RPJMN 2015-2019

FP2020

\begin{tabular}{lll}
\hline Indicator & $\begin{array}{l}\text { Current } \\
\text { number }\end{array}$ & Data Source \\
\hline Additional user & 892.299 & FPET \\
mCPR (WRA) & 45,09 & FPET \\
Unmet need for modern method (married women) & 13,8 & FPET \\
Demand satisfied (married women) & 81,1 & FPET \\
Unwanted pregnancy & 2.607 .018 & CIC \\
Averted unwanted pregnancy & 8.148 .234 & CIC \\
Averted unsafe abortion & 2.833 .141 & CIC \\
Averted maternal death & 14.830 & CIC \\
Method mix & & CIC \\
Percent SDP with stock out ${ }^{\star}$ & & CIC \\
Percent SDP with minimum 3 contraceptive methods & 87,3 & PMA \\
Annual FP expenditure & $\$ 533 \mathrm{M}$ & NIDI \\
Couple-years of protection (CYP) & 45.856 .646 & Track20 \\
Method information index & 29,3 & PMA \\
FP counseling & 14,3 & PMA \\
FP decision making & 90,8 & PMA \\
Adolescent birth rate & 48,0 & PMA \\
\hline
\end{tabular}

RPJMN 2015-2019

\begin{tabular}{llll}
\hline Indicator & Target & Current number & Data Source \\
\hline TFR & 2.36 & 2.3 & PMA \\
CPR (married women) & 65.4 & 60.2 & FPET \\
Unmet need (married women) & 10.5 & 14.6 & PMA \\
LARC user & 21.1 & 22.5 & PMA \\
Discontinuation rate & 25.7 & 27.1 & SDKI \\
\hline
\end{tabular}

Note: Data per $2015,{ }^{\beta}$ NIDI estimation, ${ }^{\star}$ data presented separately, Contraceptive Prevalent Rate (CPR), Long-Acting Reversible Method (LARC), Total Fertility Rate (TFR), modern CPR (mCPR), Core Indicator Calculator (CIC).

in many countries used active user and old user as indicator for program evaluation. However, those indicators have inconsistent definition and tend to overlap in reporting, hence they were considered less effective to measure FP2020 progress. In the additional modern method, user is defined as the difference between numbers of modern contraceptive users in the current period compared to the previous period. This indicator is considered more effective to describe FP2020 target to increase contraception users to be 120 million in 2020 and can resolve overlap in reporting.

The other global family planning indicator is unmet need among women of reproductive age (WRA). Indonesia's unmet need in 2015 was increased compared to IDHS 2012. It increased from $11.4 \%$ to $14.6 \%$ (based on PMA2020 result). Discontinuation rate among WRA also remained high. On the other hand, the PMA2020 result showed decreased number of contraception users of traditional methods. However, it seems has no significant effect to increase mCPR.

Indonesia's family planning trajectory based on current estimation is behind the target (see Picture 1). Based on three surveys in 2015 (PMA, SUSENAS, SUPAS), the CPR is projected to be 61.1 in 2020, while compared with RPJMN targets in 2019, this point is 


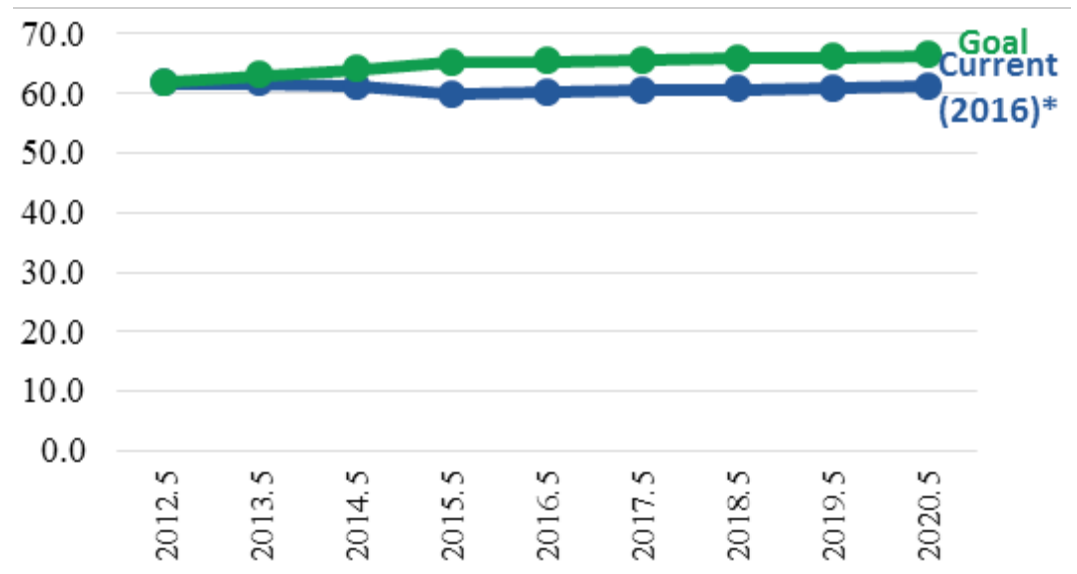

Picture 1. CPR among Married Women and Its Trajectory (2012-2020)

already 5 points lower $(66.0 \%)$ than target at the same point. Picture 1 shows that the decline of CPR began at 2014 and continued until 2015. The increase from 2016 to 2020 cannot reach the predetermined targets.

Using 2012 number as the starting point to predict probability to achieve $66.0 \% \mathrm{CPR}$ in 2019, the annual growth should have been 0.5 points. But the real growth is only 0.3 point/ year. There is 0.2 point lag accumulating since 2012 to 2016. In order to pursue the target in the coming years, the average CPR growth should be 1.5 point/year so that the targeted 66.0\% CPR in 2019 could be achieved.

The first step to identify opportunities for CPR growth space is mapping the characteristics of women reproductive age (WRA). Picture 2 showed that there were $74.0 \%$ WRA need contraceptive methods, where only $81.4 \%$ of those were satisfied by modern contraceptive method. This means that there were $18.6 \%$ WRA who needed modern methods of contraception but did not use any method to prevent pregnancy. In this section, only modern methods are considered in the analysis given its higher effectiveness than traditional methods.

Decisions about childbearing and contraceptive use are most likely to meet a person's needs when they reflect individual desires and values, are based on accurate and relevant information, and are medically appropriate; that is, when they enable informed choices. To make informed choices, people need to know about family planning, have access to various methods, and have support for individual choice from social policies and community norms. In 2015, lack of knowledge on FP access contributed $0.7 \%$ of why women of reproductive age who do not want to have child within 2 years were not using any FP method. The biggest contribution (29\%) was their concern about contraception side effects which at the same time inform us the quality of provider-client information exchange during informed choice process. Informed choice can be monitored using Method Information Index (MII). Compared to IDHS 2012, MII from PMA2020 has slightly increased but was still not high enough.

Informed choice in family planning provides many advantages to women. FP clients who choose a method with full information have higher chance to use their selected method for a longer duration than method chosen for them by others or method which they have limited information of. Furthermore, wide access to diverse contraception methods facilitates clients to choose the method they like and switch to more suitable method in accordance to their reproductive need. In contrast, lack of informed choice will contribute to higher levels of discontinuation and unmet need.

In Indonesia, method discontinuation rate in the first year after method adoption due to side effects and health concerns was quite high- about 30\% in 2012 (all methods). The highest discontinuation rates are found among implant users and injectable users, the most commonly used method in Indonesia. Although 


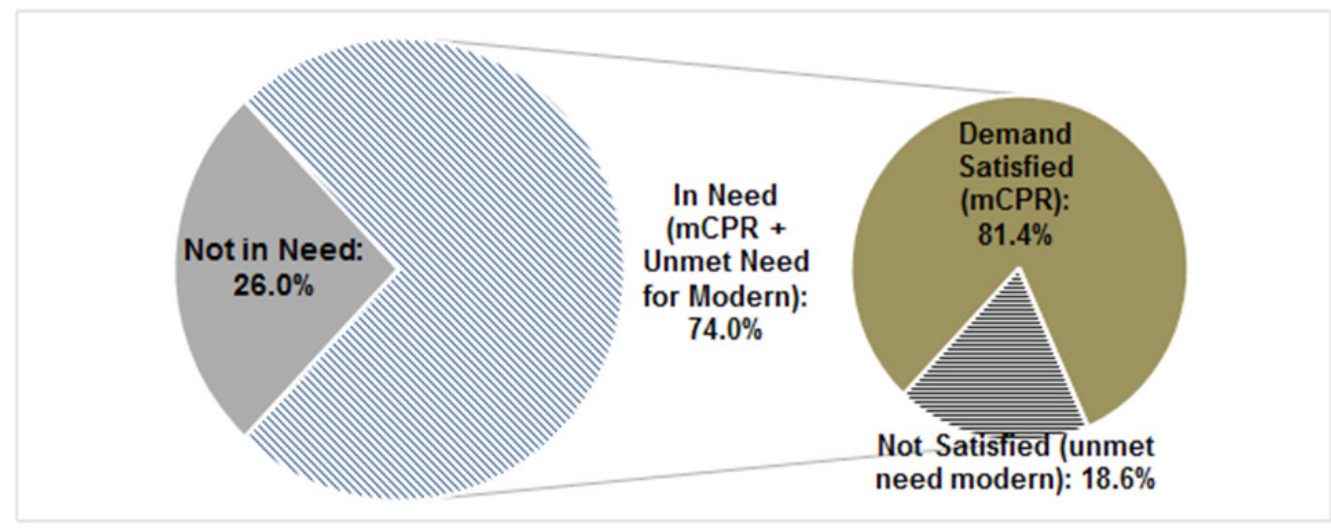

Picture 2. Characteristics of Contraceptive Need of WRA in Indonesia (3a)

the long-term trend in discontinuation rates for these two methods is one of gradual decline, the rate of discontinuation for implants increased significantly between 2007 and 2012, paralleling the decline in informed choice concerning side effects between these two surveys. Better counseling would likely enable women to be better prepared to deal with side effects, thus increasing continuation rates.

Lack of knowledge to alternative various methods of contraception also contribute to higher levels of unmet need. Unmet need may occur due to constraints in access to family planning services, availability of methods, cost and lack of knowledge of couples in their reproductive age to various methods of contraception and their side effects. Thus, increasing MII coverage is an important strategy in response to rising unmet need observed in the 2015 PMA2020 survey.

It is clear from the available data that service providers in Indonesia do not always provide complete information about contraceptive options and the pros and cons of alternative methods. This is often the result of "provider bias" - a situation in which providers prefer certain methods over others. It may occur due to family planning providers have more knowledge of certain methods that they believe are the best methods, or an inclination to promote the easiest/most profitable method, or simply the method that is being promoted by the program. Many countries, including Indonesia, explicitly promote long-acting contraceptive methods, but fail to systematically provide adequate information on such methods to clients.

Research in many countries (Morocco -dominated by pill, Vietnam, Cuba, Egypt, and Jordan -dominated by IUD, and China -dominated by tubal ligation) shows an important role of health provider in family planning decision making. In Morocco, pill is recommended due to higher acceptance rate from the community and its simplicity in the provider side. Indonesia's policy to increase use of long-acting contraceptive methods to $23.5 \%$ in 2019 (per the RPJM 2015-2019) needs to be accompanied by clearer policies prioritizing informed choice and stronger policy implementation.

Trend of Indonesia CPR seem flat when compared to other countries in the Southeast Asia region. It is caused by $\mathrm{CPR}$ position that nearly saturated. In the world, the CPR pattern followed the S-curve where the position of Indonesia has been at the top side of the $S$-curve. Countries with a rapid increase in CPR generally still in the neck of $S$ curve. Then the slow increase in Indonesia CPR is considered by many as a natural thing.

The use of modern contraceptive methods of WRA by method type showed a little skew pattern of method mix that leads to shortterm contraceptive methods by dominance of injection and pill. The pattern of method mix in many countries today is very unbalanced, with over $50 \%$ usage piled on one or two types of contraceptive methods only. The latest report says that $30 \%$ of the 109 developing countries 
experienced a skew method mix, decreased from $35 \%$ in the same analysis in 2006 . Injection user also increased while sterilization and IUD decreased (Ross et al., 2015).

The method mix skew can be caused by several things. First, the condition is an indication of a lack in adequate informed choice or MII, which summarizes whether users of family planning services received information about the various methods of contraception, side effects that may be experienced and what to do if they have it. Giving informed choice also ensure that family planning services are given in line with human rights and offer the various methods available and may be accepted by prospective user. This principle is in accordance to International Family Planning Conference (ICPD) in 1994.

The second cause of the gap in the distribution mix method is the inability of the government or the service provider to access certain types of contraceptive methods. In other countries, the reason could be because of the unpopularity of certain contraceptive methods (Ross et al., 2015). For example, in Indonesia, female condom is not as popular as male condom or bead bracelet method that actually is not widely known in Indonesia but commonly used in Africa. In some African countries, some methods cannot be accessed due to clinical problems such as the unavailable trained personnel for IUD, implant, vasectomy and tubal ligation. In practice, the imbalanced mix method can also be caused by distortions of socio-cultural norms that may conflict with the use of certain types of contraceptive methods (Sullivan et al., 2006).

The third factor is the existence of bias among health care providers in family planning services. Enthusiasm of FP service providers on a particular method raises concerns in provideruser interaction during FP counseling and decision-making process that is supposed to be autonomous for prospective users (Higgins et al., 2016, Gilliam, 2015). Research conducted by Dehlendorf found that health care providers tend to recommend IUDs and implants for black women with poor economic background (Dehlendorf et al., 2010). Effectiveness of IUDs and implants also encourage the use of this method extensively through promotive and supportive policies and resources to facilitate access. The elimination of this obstacle, by some, feared would lead FP service providers to be biased and ignores the principle of autonomy of decision-making (Gold, 2014).

Skew method mix which tends to the short-term contraceptive methods will affect the dropout rate because the access is highly dependent on the availability of method or competent provider in the health care. A study in Peru and Indonesia stated that the limited availability of modern methods is the reason of periodic abstinence (Becker \& Ahmed, 2001). $40 \%$ users of pill and injections had periodic abstinence and withdrawal will be dropped out within 12 months after use. The lowest dropout rate came from the use of intrauterine device (IUD; 13\%) and the highest from the use of condoms (50\%) (Ali et al., 2012). Reviews in 23 countries by Ali and Cleland found that among drop-out users of modern contraceptive methods, 3 months after droo-out, $26 \%$ were at risk of pregnancy, $10 \%$ became pregnant, and $60 \%$ moved to other methods (Ali \& Cleland, 2010).

The high dropout rate stressed the importance of improving the quality of service, especially counseling and informed choice (Ali et al., 2012). Number of MII recipients in Indonesia based on data from Demographic and Health Survey in 2012 was only $21 \%$, which was slightly increased in 2015 to $29.3 \%$. Provision of accurate information by healthcare workers about the timing and the type of contraceptive method will prevent unwanted pregnancies (Ali et al., 2012).

One strategy that can be done to improve CPR when the distribution is skewed is by providing one additional method with sufficient availability for half of the target population in the area. This strategy, based on research by Ross and Stoner for 27 years in 113 countries, were able to increase the use of modern contraceptive methods by $4-8 \%$ (Ross \& Stover, 2013). Another example of this strategy's application was the sharp increase when IUD and pill contraceptives were introduced in four Asian countries in 1960-1970s (Freedman \& Berelson, 1976).

In 2016, from 30.8 million estimated users of modern family planning in Indonesia, we 


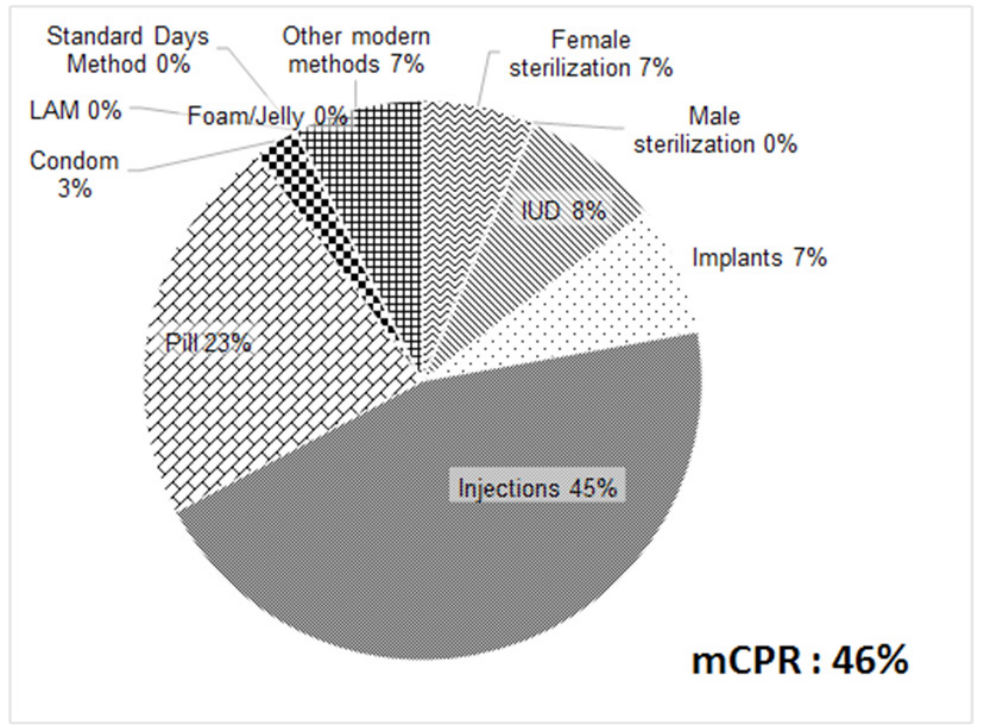

Picture 3. Method Mix in Indonesia Year of 2015

will prevent 8 million of unwanted pregnancy, almost 3 million unsafe abortions, and in total there are nearly 15,000 mothers saved from mortality. Three indicators of the impact of family planning in this FP2020 be a very clear picture of the benefits of family planning interventions for the health of maternal, child and family in Indonesia. By investing in the program, we can encourage more women and their families in decision control about when and how many children they should have so unwanted pregnancy and its negative effects can be reduced.

The current trend shows that Indonesia should have more than 4 million additional users from 2012 until 2020 to reach the target of FP2020. Additional contraceptive user can be achieved by lowering unmet need, increasing the promotion of family planning programs and maintaining active user as well as ensuring the availability of contraceptive commodities in healthcare services.

Based on Netherlands Interdisciplinary Demographic Institute (NIDI) estimation on 2015, Indonesian national spending resources in the field of family planning is shown in Picture 3. Indonesia's expenditure is larger than India, but nearly two-thirds of it come from the user's pocket. This could be a sign that the Indonesia family planning program strategies in the form of a guaranteed supply of free contraceptives across the country through
National Health Insurance scheme is still not visible. In line with the NIDI, PMA2020 data also showed that more than $50 \%$ of government family planning service providers in various level of services, charged the cost for family planning service provided (Wilopo et al., 2016).

One of contraceptive use barrier is method's availability. The first round of PMA2020 data showed that availability of minimum three contraceptive method in primary public health care (Puskesmas) was better than the private. But in the secondary level of health services (hospital), private was better that public. Urban and rural area have same pattern on method availability (for details see Picture 4).

Wang analysis on the DHS data showed that an increase in the supply of family planning needs have a positive effect on the prevalence of contraceptive use. Contraception use was significantly associated with the availability of contraceptive methods at the nearest health facility. Factors that influence the supply of the intention of the use of contraception was not only from the commodities aspect, but also the number of nurses and trained personnels (Wang et al., 2012).

The dynamics of dropout rates, change of methods, and contraceptive failure is the important indicators of family planning program service quality. Whether or not, it met the needs of WRA and couple. Studies 


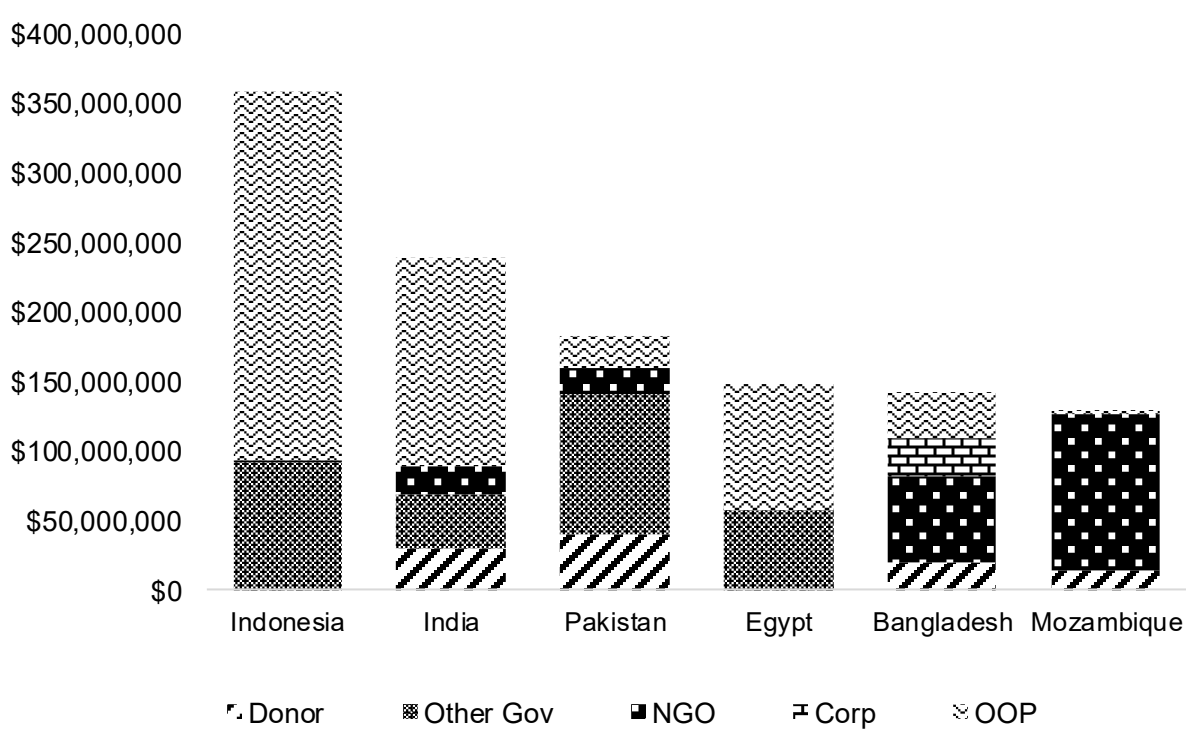

Picture 4. Total Family Planning Expenditure

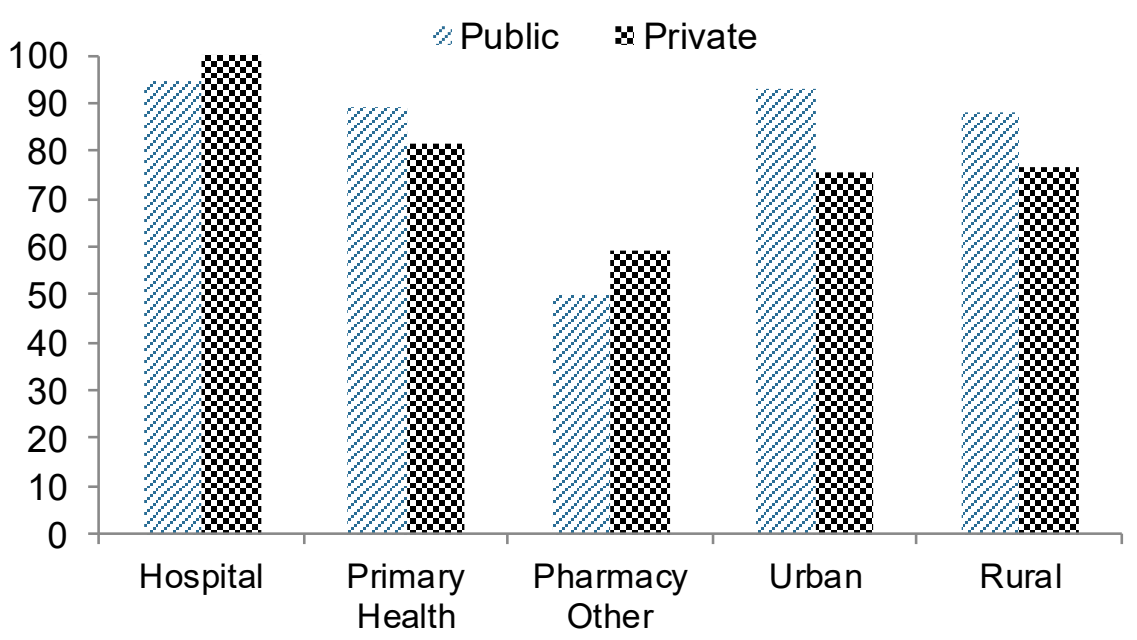

Picture 5. Percent facility with minimum three modern methods available

conducted by Mensch proved that the prevalence of contraception users among women who live in areas with high quality of family planning services would be $16-23 \%$ higher than areas with poor quality of family planning services (Mench et al., 1996). In the dimension of service, there are four aspects that must be met by healthcare providers to provide good family planning services. The first aspect is family planning counseling where the facility should have a counseling area that ensures both audio and visual privacy of users. Facilities must also have visual equipment method, recording separately for each client and written guidance/ manual on family planning.

The second aspect of good quality of family planning services is the availability of potential infection control with running water, hand soap, hand disinfectant, sharp object container object and rubber gloves. The next is soundproof and closed pelvic examination facilities, a lamp and a table as well as vaginal speculum. The last, management aspect, consist of availability of trained staffs to carry out family planning services and regular supervision of internal and external stakeholders (Wang et al., 
2012).

\section{Conclussion}

Based on the latest data survey in 2015, the trend of CPR will be five points lower than target. Acceleration of CPR may be achieved by lowering unmet need, drop-out rate, encourage the use of modern contraceptive methods as well as providing supportive policies and resources to ensure the availability and quality of family planning methods.

\section{Acknowledgements}

We would like to acknowledge the assistance of Avenir Health for Track20 in the using the software.

\section{Refferences}

Ali, M.M., \& Cleland, J., 2010. Contraceptive Switching after Method-related Discontinuation: Levels and Differentials. Studies in Family Planning, 41, pp.129-133.

Ali, M. M., Cleland, J., \& Shah, I., 2012. Causes and Consequences of Contraceptive Discontinuation: Evidence from 60 Demographic and Health Surveys.

Ayuningtyas, D., Oktaviana, W., \& Misnaniarti., 2015. Factors Contributing to Unmet Need for Contraception in Nusa Tenggara Barat, Indonesia. Journal of Reproduction and Contraception, 26, pp. 239-248.

Becker, S., \& Ahmed, S., 2001. Dynamics of Contraceptive Use and Breastfeeding during the Post-Partum Period in Peru and Indonesia. Population Studies, 55, pp.165179.

Cleland, J., Shah, I.H., \& Benova, L., 2015. A Fresh Look at the Level of Unmet Need for Family Planning in the Postpartum Period, Its Causes and Program Implications. Int Perspect Sex Reprod Health, 41, pp.155-62.

Conde-Agudelo, A., Rosas-Bermudez, A., \& KafuryGoeta, A.C., 2007. Effects of Birth Spacing on Maternal Health: A Systematic Review. Am J Obstet Gynecol, 196, pp.297-308.

Dehlendorf, C., Ruskin, R., Grumbach, K., Vittinghoff, E., Bibbins-Domingo, K., Schillinger, D., \& Steinauer, J., 2010. Recommendations for Intrauterine Contraception: A Randomized Trial of the Effects of Patients' Race/Ethnicity and Socioeconomic Status. Am J Obstet Gynecol, 203, pp.319.

Freedman, R., \& Berelson, B., 1976. The Record of Family Planning Programs. Stud Fam Plann, 7, pp.1-40.

Gilliam, M.L., 2015. Beyond Coercion: Let Us
Grapple With Bias. Obstet Gynecol, 126, pp.915-6.

Gold, R.B., 2014. Guarding Against Coercion while Ensuring Access: A Delicate Balance. Guttmacher Policy Review, 17, pp.8-14.

Higgins, J.A., Kramer, R.D., \& Ryder, K.M., 2016. Provider Bias in Long-Acting Reversible Contraception (LARC) Promotion and Removal: Perceptions of Young Adults. Am J Public Health, 106(11), pp.1-6.

Mensch, B., Arends-Kuenning, M., \& Jain, A., 1996. The Impact of the Quality of Family Planning Services on Contraceptive Use in Peru. Stud Fam Plann, 27, pp.59-75.

Moore, Z., Pfitzer, A., Gubin, R., Charurat, E., Elliott, L., \& Croft, T., 2015. Missed Opportunities for Family Planning: An Analysis of Pregnancy Risk and Contraceptive Method Use among Postpartum Women in 21 Low- and MiddleIncome Countries. Contraception, 92, pp.319.

Nugroho, E., Shaluhiyah, Z., Purnami, C.T.K., 2017. Counseling Model Development Based on Analysis of Unwanted Pregnancy Case in Teenagers. Jurnal Kesehatan Masyarakat, 13(1).

Ross, J., Keesbury, J., \& Hardee, K., 2015. Trends in the Contraceptive Method Mix in Low- and Middle-Income Countries: Analysis Using A New "Average Deviation" Measure. Glob Health Sci Pract, 3, pp.34-55.

Ross, J., \& Stover, J., 2013. Use of Modern Contraception Increases when More Methods Become Available: Analysis of Evidence from 1982-2009. Glob Health Sci Pract, 1, pp.203-12.

Ross, J.A., \& Winfrey, W.L., 2001. Contraceptive Use, Intention to Use and Unmet Need during the Extended Postpartum Period, International. Family Planning Perspectives, 27(1), pp.2027.

Sullivan, T.M., Bertrand, J.T., Rice, J., \& Shelton, J.D., 2006. Skewed Contraceptive Method Mix: Why It Happens, Why It Matters.J Biosoc Sci, 38, pp.501-21.

Wang, W., Wang, S., Pullum, T., \& Ametepi, P., 2012. How Family Planning Supply and The Service Environment Affect Contraceptive Use: Findings from Four East African Countries. DHS Analytical Studies No. 26. Calverton, Maryland, USA: ICF International.

Wilopo, S.A., Magnani, R. J., Pinandari, A.W., \& Wahdi, A.E., 2016. Indonesia: Assessing our Progress toward 2020. In: UGM, Center for Reproductive Health Faculty of Medicine. Yogyakarta: Center for Reproductive Health. 